\title{
LEXICULTURA DO SERTÃO: UMA PROPOSTA DIDÁTICA PARA ESTUDANTES DA EDUCAÇÃO PROFISSIONAL NO SEMIÁRIDO BAIANO
}

\section{SERTÃO'S LEXICULTURE: A TEACHING PROPOSAL FOR PROFESSIONAL EDUCATION STUDENTS IN BAHIA}

\author{
Elisângela Isabel Cardoso ${ }^{1}$ \\ Alex Batista Lins ${ }^{2}$ \\ Instituto Federal de Educação, Ciência e Tecnologia da Bahia (IFBA)
}

\begin{abstract}
RESUMO
A escola deve ter como objetivo formar cidadãos críticos e respeitadores da diversidade cultural e linguística em que está inserida. Para isso, faz-se necessário conhecer os falares e a cultura nos quais está inserido. Através do estudo da lexicografia regional, o aluno poderá desvendar a existência do outro ao seu redor, e ao romper uma visão limitada sobre a língua, possibilitará ao educando o desenvolvimento de seu universo de entendimento, seu horizonte de expectativas. Assim surgiu a proposta de realizar uma oficina pedagógica com turmas do $1^{\circ}$ ano de uma escola de Educação Profissional e Tecnológica, na cidade de Uauá- BA, com a finalidade de incentivar o respeito ao falar próprio da região, utilizando como instrumento de motivação a pesquisa de verbetes específicos do município. Baseado nestes aspectos o processo da oficina resultará na construção de um dicionário regional destacando como fundamentação teórica a lexicultura com base em Aragão (2010), Isquerdo (2003) e Barbosa (2009). A abordagem metodológica utilizada para o desenvolvimento da oficina será a sócio interacionista. Nesse sentido, este trabalho poderá trazer consequências positivas, pois o conhecimento de mundo dos alunos inseridos na pesquisa se ampliará, através da aprendizagem por meio da construção do dicionário e da contribuição no combate ao preconceito linguístico.
\end{abstract}

PALAVRAS CHAVE: Dialeto, Cultura, Lexicografia, Lexicultura.

\begin{abstract}
The school should aim to educate critical citizens who respect the cultural and linguistic diversity in which it operates. For this, it is necessary to know the speech and the culture in which it is inserted. Through the study of regional lexicography, the student can unveil the existence of the other around him, and by breaking a limited view of the language, will enable the student to develop the universe of understanding, their horizon of expectations. Thus the proposal came to hold a pedagogical workshop with first year classes of a school of Vocational and Technological Education, in the city of Uauá-BA, with the purpose of encouraging respect for speaking in the region, using as a motivation tool the research. Based on these aspects the workshop process will result in the construction of a regional dictionary highlighting as lexiculture based on the authors Aragão (2010), Isquerdo (2003) and Barbosa (2009). The methodological approach used for the development of the workshop will be the interactionist partner. In this sense, this work may have positive

\footnotetext{
${ }_{1}$ Professora de Língua Portuguesa do Centro Territorial de Educação Profissional e Tecnológica Sertão do São Francisco II - Antônio Conselheiro - CETEP - SSF II. Mestranda em Educação Profissional e Tecnológica pelo Instituto Federal de Educação, Ciência e Tecnologia da Bahia (IFBA). E-mail: elisisabel@hotmail.com

2 Professor EBTT de Língua Portuguesa do Instituto Federal de Educação, Ciência e Tecnologia da Bahia (IFBA). Doutorado em Letras e Linguística pela Universidade Federal da Bahia (UFBA). E-mail:
} alex06xp@yahoo.com.br
\end{abstract}


consequences, as the students' knowledge of the world will be expanded through learning through the construction of the dictionary and the contribution to the fight against linguistic prejudice. of encouraging respect for speaking in the region, using as a motivation tool the research.

KEYWORDS: Dialect, Culture, Lexicography, Lexicology.

\section{INTRODUÇÃO}

A compreensão da língua necessita de reflexão sobre a cultura da qual o sujeito faz parte, pois ela está inserida num contexto amplo que envolve não só a comunicação, mas a cultura, o nível de escolaridade, a classe social e a região de cada um.

Diante dessa realidade, é pertinente reforçar atividades escolares que envolvam as diversas variedades da língua e que apresentem o conhecimento cultural brasileiro como algo precioso e merecedor de estudo e respeito. Sendo assim, este trabalho tem o intuito de apresentar uma proposta didática de produção lexicográfica a partir de verbetes específicos do município de Uauá - Bahia. O arcabouço teórico está pautado principalmente em Aragão (2010), Isquerdo (2003) e Barbosa (2009).

Considerando a importância de se trabalhar a produção lexicográfica regional com a finalidade de motivar a curiosidade e o respeito dos alunos para com o falar específico de sua comunidade, procuramos desenvolver uma proposta de trabalho baseada na oficina pedagógica com o gênero textual literatura de cordel e o estudo sobre verbete. $\mathrm{O}$ gênero cordel foi escolhido porque serão utilizados textos de cordelistas locais, fato esse que favorece o reconhecimento dos falares da comunidade a qual os educandos estão inseridos. Já o estudo sobre verbete servirá de suporte para a construção do dicionário regional. Nosso objetivo é oferecer atividades através de pesquisas lexicográficas que possam ser adaptadas e aplicadas por professores de outras regiões. Para a análise dos verbetes coletados durante a pesquisa dos alunos será necessário fazer a conexão com a carga cultural ligada ao léxico do sertão, ideia trabalhada por Barbosa (2009), no conceito de lexicultura, ou seja, uma união entre o léxico e a cultura, que compreende a herança cultural de um grupo ou local, através das palavras e dos costumes entrelaçados ao falar e entender de um grupo.

Este artigo está organizado em cinco seções: na primeira, apresentaremos um panorama da Língua Portuguesa na Educação Profissional e Tecnológica. A segunda abordará aspectos que constituem a Lexicografia regional e a lexicultura. Na terceira seção, faremos a apresentação do Gênero Cordel. Na quarta, justificaremos a escolha do estudo sobre o verbete e, na quinta e última seção, exibiremos a apresentação da proposta didática por meio do plano de ação da oficina pedagógica que inclui a atividade de pesquisa de campo a ser desenvolvida com turmas do primeiro ano do Ensino Médio da Educação Profissional e Tecnológica.

Nesse sentido, este trabalho poderá trazer consequências positivas, pois o conhecimento de mundo dos alunos inseridos na pesquisa se ampliará, através da aprendizagem por meio da construção de verbetes e dicionários e da redução do preconceito linguístico.

\section{0 ensino da Língua Portuguesa na EPT ${ }^{3}$}

Sendo a língua uma representação da realidade social, uma maneira do indivíduo interagir e envolver-se no mundo que o cerca, ela é indispensável para que o educando construa conhecimentos, relacione-se com a realidade, emancipe-se enquanto cidadão.

\footnotetext{
${ }^{3}$ Educação Profissional e Tecnológica
} 
Dessa forma, o ensino da Língua Portuguesa, especificamente na EPT, necessita de um permanente intercâmbio entre as disciplinas, compreendendo as relações específicas das estruturas sociais e das práticas sócio discursivas pertencentes a tais estruturas. Isso significa que saber usar a língua materna de forma adequada não é apenas dominar regras gramaticais, mas sim saber comunicar-se em diversas situações discursivas. Faraco (2002, p.104) reforça esta concepção ao afirmar que

Esse pensar envolve a compreensão não só da realidade estrutural da língua, mas, acima de tudo, de sua realidade social e histórica (a língua como um conjunto múltiplo e entrecruzado de variedades geográficas, sociais, estilísticas, de registros e de gêneros discursivos) entendendo-a como correlacionada com a vida e a história dos diferentes grupos sociais, desenvolvendo a crítica dos preconceitos linguísticos, estimulando práticas positivas diante das diferenças e contribuindo assim para a reconstrução do imaginário nacional sobre a nossa realidade linguística.

No entanto, o ensino de Língua Portuguesa da Educação Profissional, em geral, enfatiza a variedade culta exigida pelo mercado de mercado. Há uma "verdade" préconcebida entre os docentes da Educação Profissional, especialmente os de Língua Portuguesa, que se deve trabalhar em cursos profissionalizantes a variedade culta e os termos técnicos de cada área, esquecendo-se de que grande parte dos profissionais precisará interagir com outros falantes da região e que eles necessitarão ter uma visão de reconhecimento do dialeto local e de postura que não dissemine o preconceito linguístico.

Conhecer, reconhecer, aprender e relacionar-se utilizando as variações linguísticas, as quais representam a forma natural pela qual utilizamos a língua para nos comunicar, nas diversas situações linguísticas é uma competência necessária para que o estudante conviva no mundo do trabalho como um agente político, apto a colaborar, transformar e interagir "com" e "no" ambiente profissional.

\section{A lexicografia regional e a lexicultura}

Ao tratar do léxico, é necessário lembrar que ele registra a realidade vivida por uma população, representando o vocabulário de tal comunidade, seus valores e crenças, levando essa nomeação para futuras gerações, documentando sua existência para a história. Segundo Isquerdo (2003), o repertório lexical da comunidade linguística apresenta-se renovado por fatores históricos, geográficos e culturais. $\mathrm{O}$ vocabulário que a comunidade linguística utiliza reflete as idiossincrasias da formação étnica da coletividade.

Assim, é importante destacar que, ao se considerar o léxico de uma língua como um registro histórico-cultural de um povo, acredita-se também no prestígio dessa língua e, consequentemente, da própria comunidade que fala essa língua.

Devido à grandeza de vocabulário em cada comunidade linguística, mostra-se indispensável o trabalho de sistematização de tais vocábulos, através de suas coletas e descrições. Apresenta-se, então a necessidade da construção de dicionários regionais.

Biderman (2001) afirma que "os dicionários constituem uma organização sistemática do léxico, uma espécie de tentativa de descrição do léxico de uma língua". Dessa forma, a autora reforça a importância dos dicionários, pois pelo fato de eles descreverem a estrutura lexical de uma língua, acabam representando a memória coletiva de um povo.

Contudo, faz-se necessário destacar que a elaboração de um dicionário regional é complexa e demanda dedicação e esforço do pesquisador, tendo em vista que o próprio conceito de regional possui difícil definição e compreensão. Sobre essa realidade, é importante destacar o fenômeno da variação linguística no que se refere ao regionalismo: 
Tratar da questão dos regionalismos implica levar em consideração a questão da norma linguística no nível lexical, o que nos remete à questão da variação. Assim, as marcas dialetais no âmbito do vocabulário de um grupo sóciolinguístico-cultural relacionam-se diretamente à variação espacial (regionalismos) e à variação temporal (arcaísmos). (ISQUERDO, 2003, p. 166)

Os regionalismos são caracterizados por expressões típicas que se apresentam relacionadas a uma região específica, contudo há uma dificuldade de estabelecer o ponto de referência para definir o termo como regional, ou como uma variedade de gênero, etário, dentre outros. 139) explica:

Ao relacionar o conceito de regionalismo à realidade brasileira, Biderman (2001, p.

\begin{abstract}
Qualquer fato linguístico (palavra, expressão, ou seu sentido) próprio de uma ou de outra variedade regional do português do Brasil, com exceção da variedade usada no eixo Rio/São Paulo, que se considera como português brasileiro padrão, isto é, a variedade de referência, e com exclusão também das variedades usadas em outros territórios lusófonos.
\end{abstract}

Pode-se afirmar, ainda, que a dificuldade de estabelecer os regionalismos também ocorre pelo fato de que as expressões que representam o léxico de duas ou mais regiões e movem-se por meio de processo migratório e êxodo rural acabam por espalhar tais vocábulos pertencentes à região de origem do falante.

Sendo assim, como afirma Biderman (2001), os dicionários regionais são obras que apresentam variedades encontradas em determinadas regiões do Brasil fora do eixo Rio-São Paulo, tido como o falar padrão brasileiro.

Nota-se uma tendência de estudos dialetais e sociolinguísticos com enfoque na lexicografia regional, mais precisamente na publicação de dicionários, vocabulários e glossários de falares regionais nordestinos.

Segundo Aragão (2010), uma das características dos novos dicionários, vocabulários e glossários é que seus autores não são lexicógrafos ou linguistas. São pessoas com outras formações profissionais: jornalistas, engenheiros, médicos, folcloristas ou pessoas curiosas que resolveram listar e publicar, em forma de dicionário, palavras e expressões populares que, creem eles, são típicas daquele estado específico.

A partir do momento que se tem a língua como objeto de estudo, os contextos socioculturais em que ela está inserida são elementos básicos e também determinantes de suas variações, explicando e justificando fatos que apenas linguisticamente seriam difíceis ou até impossíveis de serem explicados, pois, como afirma Aragão (2010, p. 01) "Língua, sociedade e cultura são indissociáveis, interagem continuamente, constituem, na verdade, um único processo complexo...”

Ao se referir no caso específico do léxico, esta afirmação é ainda mais verdadeira, pois toda a visão de mundo, a ideologia, os sistemas de valores, as tradições, as práticas socioculturais e consequentemente a história das comunidades humanas é refletida em seu léxico.

Ainda segundo Aragão (2010, p. 02): “... o léxico representa, por certo, o espaço privilegiado desse processo de produção, acumulação, transformação e diferenciação desses sistemas de valores."

Portanto, para se identificar, compreender, descrever, analisar e explicar a "visão de mundo" de um povo é inquestionável de que o objeto de estudo principal sejam as unidades lexicais e suas relações nos contextos dessa população.

Sendo assim, a lexicultura é um termo que nasce da compreensão de que o léxico é um instrumento linguístico disseminador de significados e, por isso difusor da cultura. É ele quem determina a relação entre língua e cultura e "nos auxilia a compreender e a 
explicar a sociedade da qual fazemos parte ou à qual pretendemos ou queremos aceder" (BARBOSA, 2009, p.32).

O termo lexicultura resulta, de acordo com Guillén Diaz (2003, p. 25 apud BARBOSA, 2009, p. 33)

(...) da junção de léxico e cultura, os quais remetem, respectivamente, ao conjunto de ULs de uma língua e ao conjunto de manifestações do cotidiano de um povo expressas pelo léxico. Essa carga cultural compartilhada é observável nas locuções cristalizadas, como as EIs, motivo pelo qual as consideramos um conteúdo, além de lexical, lexicultural. Nelas, as associações estabelecidas, muitas vezes ilógicas e bizarras, conotam uma significação que extrapola a relação primária entre o significante e o significado.

No contexto de ensino-aprendizagem em Língua Portuguesa, os educandos apresentam dificuldades em realizar atividades com léxico, pois, como explica Barbosa (2009, p. 32), os aprendizes deparam-se com um vocabulário que difere daquele ao qual estão habituados a utilizar e dominam.

Assim, no momento em que o dicionário oferece apenas definições que seguem um padrão clássico, ele deixa de proporcionar ao pesquisador o conhecimento pleno das entradas. Portanto, a informação lexicultural pode ser proposta no interior do verbete de maneiras diversas. Podemos informar sobre $\mathrm{ULs}^{4}$ culturalmente marcadas explorando sua simbologia, as relações analógicas que as permeiam bem como apresentando informações relativas à etimologia propriamente dita e à etimologia popular. (PRUVOST apud BARBOSA, 2009)

\section{A Literatura de cordel}

A literatura popular prescinde, e muito, o surgimento da escola. Os artistas populares já criavam poesias animando os saraus da alta nobreza na Grécia Antiga e no Império Romano. (ALENCAR, 2008, p.02).

A literatura de cordel, por exemplo, é um gênero literário popular criado em forma rimada, originada em relatos orais e depois impresso em folhetos. Teve seu início no século XVI em Portugal, quando o Renascimento popularizou a impressão de relatos orais, e mantém-se como uma forma literária popular no Brasil. O nome "cordel" também teve origem em Portugal, devido à maneira como os textos escritos em folhetos eram expostos para venda, ou seja, pendurados em cordas, cordéis ou barbantes. (LUYTEN, 1992, p. 30)

Quando chegou ao Brasil, entre 1840 e 1850, a literatura de cordel trazia as narrativas circunstanciais do povo, "surgiu e se fixou no Nordeste como uma das peculiaridades da cultura regional" (ALENCAR, 2008, p.03).

Ler cordel não é uma prática usual das novas gerações, já que estes têm a "televisão e a internet ocupando o espaço do imaginário infantil" (BUSSATO, 2008, p.55). Assim, é tarefa primordial da escola o resgate dessa capacidade de mover-se entre o imaginário e o infantil que nossos adolescentes estão perdendo em detrimento da troca do imaginário criativo pelo que guardam na "memória televisiva". É limitado o espaço dado ao cordel no cotidiano escolar, mas graças ao trabalho dos poetas, o cordel, impresso ou declamado, obteve destaque em movimentos ligados à cultura, amplificando o Nordeste, suas tradições, sua arte e seu povo.

O cordel aparece na escola com carência, fator que preocupa tanto aos poetas quanto aos poucos professores adeptos à leitura deste gênero na escola. É nela, enquanto

\footnotetext{
4 Unidades Lexicais - O conceito de unidade lexical foi introduzido por Michael Lewis (1993, 1997, 2000), um dos fundadores da Abordagem Lexical. Ele sustenta que o termo unidade lexical é muito vasto e abarca diversos dos aspetos (linguísticos e culturais) a que se submete o ensino-aprendizagem de uma língua.
} 
espaço de construções, que os jovens têm acesso aos diversos gêneros, e assim deveria ser com o cordel, mas não é com frequência que encontramos professores utilizando esse recurso em sala de aula.

Marcando a importância da literatura de cordel na cultura e na formação do sujeito, levar o gênero para a escola não representa dificuldade, desde que o professor seja conhecedor e apreciador da literatura de cordel, conduzindo os alunos à apreciação deste. Segundo Melo (2009, p.05)

É urgente destacar-se a importância do cordel como elemento identitário da cultura popular, que permite ao leitor um passeio pelo imaginário, favorecendo a integração entre o real e a fantasia. A linguagem simples e a originalidade das histórias são atrativas à leitura do cordel, por isso, lamenta-se que a escola não o trabalhe com frequência.

Portanto, a literatura de cordel, instrumento precioso de valorização da identidade regional, tem nas populações mais humildes seus mais constantes e fiéis consumidores, sendo através dos tempos respeitada e considerada como a verdadeira e autêntica literatura do homem nordestino, o livro de estimação do povo da região. Dessa forma, nada mais rico do que unir o cordel à literatura clássica na sala de aula, propiciando, assim, o reconhecimento da literatura local, tão importante quanto as demais literaturas nacionais ou internacionais.

\section{$3 \mathrm{O}$ verbete em sala de aula}

O estudo do verbete abrange a análise sobre definição e exposição de termos específicos. É necessário que haja a definição de um termo levando em consideração seus sentidos denotativos e conotativos, além de generalizações e particularizações referentes ao uso do termo em variados contextos.

No âmbito dos estudos lexicográficos, o verbete corresponde a essa "definição popular ou espontânea" um pouco mais elaborada e registrada num dicionário ou glossário. O verbete apresenta uma reunião de significados e exemplos e, em alguns casos, a categoria gramatical e o gênero. Ainda segundo Dionísio (2007) os principais campos constituintes do verbete são:

Verbete $=$ entrada + categoria gramatical + fonte + área + definição + contexto.

A utilização de verbetes no processo de ensino-aprendizagem poderá contribuir para o desenvolvimento da leitura e da escrita dos alunos, pois a leitura de dicionários é uma prática defendida por aqueles que trabalham com a escrita, porém quase sempre recusada por alunos, talvez pela forma como geralmente são trabalhados em sala de aula, de maneira cansativa, maçante, sem criatividade.

\section{Descrição da Proposta Didática}

Há na escola, não raramente, uma rotina cansativa e maçante em que professores e alunos são submetidos à repetição de práticas de ensino-aprendizagem clássicas, sem muito espaço para a participação ou a criatividade. No entanto, é possível mudar essa realidade através da adoção de uma metodologia relativamente simples e que, em geral, surte grandes resultados: a oficina pedagógica, um espaço em que os ideais de transformação e diálogo na escola são realidades em permanente construção.

Sendo assim, a oficina pedagógica é uma metodologia de trabalho em grupo, caracterizada pela construção coletiva de um saber, de análise da realidade, de confrontação 
e intercâmbio de experiências, em que o saber não se constitui apenas no resultado final do processo de aprendizagem, mas também no processo de construção do conhecimento.

A aplicação dessa atividade através de oficina pedagógica se justifica justamente pela dinamicidade das atividades e especialmente pela abertura da participação ativa dos alunos em todo processo. Além disso, trata-se de um instrumento valioso para a realização da pesquisa colaborativa, ou seja, a pesquisa envolvendo a participação direta dos sujeitos.

A oficina pedagógica intitulada "Nossa Cultura, Nossa Língua" será desenvolvida com uma turma do Ensino Médio em uma escola de Educação Profissional e Tecnológica do município de Uauá - Bahia, com o intuito de se desenvolver atividades que valorizem a variedade linguística dos educandos através do trabalho lexicográfico, bem como proporcionar momentos de conhecimento da riqueza cultural e linguística da região.

\subsection{Detalhamento da oficina pedagógica:}

A oficina pedagógica será estruturada em duas etapas organizadas da seguinte forma:

Apresentação: A oficina começará com a apresentação do tema, fazendo uma breve descrição teórica do assunto bem como da sua importância no contexto da sua aplicação.

Objetivos: Neste item são indicados os objetivos os quais os alunos deverão alcançá-los no final da realização da oficina pedagógica.

Público-alvo: Estudantes do $1^{\circ}$ ano do Ensino Médio da Educação Profissional e Tecnológica do município de Uauá - Bahia. Os participantes da oficina, em sua maioria, residem na zona rural do município, nas seguintes localidades: Santana, Barriguda, Volta, Ouricuri, Queimadas, Caratacá e Caldeirão do Almeida.

Carga horária: Mostra a duração de cada etapa da oficina.

Metodologia: Na metodologia é descrito todo o processo de operacionalização da oficina. Este processo está organizado em quatro itens são eles: atividade integradora, a investigação do conceito; aplicação do tema e socialização da aprendizagem que serão cada um descrito detalhadamente a seguir:

a. Atividade integradora: Ao iniciar a oficina os alunos serão motivados a participar de uma dinâmica de integração com o intuito de observar conhecimentos prévios dos alunos e iniciar os trabalhos.

b. Investigação do conceito: Consiste em fazer um levantamento de informações sobre o assunto. $\mathrm{O}$ aluno sob orientação do professor neste momento irá ler, pesquisar, assistir um vídeo, analisar uma imagem, a fim de aprofundar-se sobre o tema.

c. Aplicação do tema: Momento em que os alunos em grupos irão partir para pesquisa de campo a fim de construir o trabalho lexicográfico relacionado ao dialeto regional.

d. Socialização da aprendizagem: Momento em que serão socializados os trabalhos produzidos pelos alunos na pesquisa de campo, para todos conhecerem e perceberem os verbetes coletados pelos colegas e finalmente unir todo material para a construção do dicionário regional. 
e. Avaliação: Em todo processo de aprendizagem, a avaliação é relevante. Para que uma proposta de aula, um estudo científico se mostre consistente e coerente com seus objetivos de ensino e expectativas de aprendizagem é preciso avaliar que consiste em: estabelecer conclusões, ouvir as opiniões, compartilhar e definir produtos finais reconhecer as produções dos alunos após a realização da oficina.

\subsection{Plano de ação}

\subsubsection{Apresentação:}

A oficina "Nossa Cultura, Nossa Língua" surgiu com a finalidade de incentivar o respeito às variedades da nossa língua, utilizando como instrumento de motivação a pesquisa de verbetes, expressões, causos e ditados específicos da nossa região. O envolvimento dos alunos representa um dos pontos principais da oficina, pois eles terão papel essencial na construção do produto final da oficina: O Dicionário Regional de Uauá.

\subsubsection{Objetivo:}

Promover momentos de valorização das variedades linguísticas regionais, estimulando os alunos a reconhecer a riqueza da linguagem local por meio de produções escritas enfatizando o uso do gênero cordel e da construção de um dicionário regional.

\subsubsection{Carga Horária:}

A primeira etapa terá 4 horas-aula (cada hora-aula possui cinquenta minutos). A segunda etapa 4 horas-aula, acrescida do período da pesquisa extraclasse a ser realizada pelos alunos.

\subsubsection{Metodologia:}

A oficina pedagógica será desenvolvida utilizando a abordagem metodológica sócio interacionista, uma vez que os Parâmetros Curriculares Nacionais do Ensino Médio (PCNEM/1999, p.11) afirmam que "não há linguagem no vazio, seu grande objetivo é a interação, a comunicação com o outro, dentro de um espaço social...”.

Nessa perspectiva, parte-se do pressuposto de que a língua não está dissociada da prática social, ou seja, a interação é o que faz com que a linguagem seja comunicativa, provocando mudanças significativas no ensino de língua portuguesa. Haverá a preocupação em desenvolver neste projeto

[...] uma gramática que ultrapassa o nível da palavra e da frase e que traz nova orientação para o ensino da leitura e da produção de textos; sobretudo uma nova concepção de língua: uma concepção que vê a língua como enunciação, discurso, não apenas como comunicação, que, portanto, inclui as relações da língua com aqueles que a utilizam, com o contexto em que é utilizada, com as condições sociais e históricas de sua utilização. (SOARES, 1998, p.46).

\section{$1^{a}$ etapa - O cordel na sala de aula}

\section{a. Atividade integradora:}

Os alunos irão assistir ao vídeo "Dias de Feira em Uauá" o qual apresenta tradições culturais e artísticas do município. Dessa forma, os educandos poderão estar mais 
próximos do tema trabalhado, já que os materiais dos artistas que serão estudados fazem parte da vida da turma. Assim, os alunos terão a oportunidade de estar diretamente inseridos, fazendo parte e interagindo com tudo o que será desenvolvido durante a oficina. Em seguida, faremos uma roda de conversa em que os alunos serão incentivados a relatar os costumes de cada localidade.

\section{b. Investigação do conceito:}

A valorização da cultura da região será feita através do trabalho sobre o cordel. Assim sendo, trabalharemos este gênero, por meio de um texto impresso retirado da apostila "Alfabetização e Letramento" de Maviael Melo ${ }^{5}$. Cada aluno irá ler um trecho da apostila e quando necessário faremos comentários. O texto é de fácil compreensão, pois seu formato de entrevista, com perguntas e respostas, expõe o assunto de maneira clara e objetiva.

Em seguida, os alunos terão contato com vários livretos de literatura de cordel, canções folclóricas locais, vídeos de cordelistas do município, para que percebam como o falar local é rico de significados e como este dialoga com a história e a cultura da região. A escolha do gênero cordel justifica-se pelo fato de que este gênero representa o dialeto dos alunos participantes, o que propiciará o reconhecimento da identidade linguística do sertão e dessa forma os estudantes compreenderão que é um dialeto que deve ser respeitado e valorizado.

\section{$2^{a}$ etapa - A valorização dos nossos falares}

\section{c. Aplicação do tema:}

Nesta etapa será trabalhado o estudo sobre a construção do verbete. Em relação ao nosso trabalho de elaboração de um dicionário com termos regionais de Uauá, optamos por uma construção mais simples do verbete, ao que foi apresentado por Dionísio (2007), para que seja um trabalho de fácil entendimento para os alunos, buscamos a construção de verbetes com uma estrutura menos complexa, porém contendo os elementos básicos. Portanto, nosso trabalho será desenvolvido com os seguintes campos constituintes:

$$
\text { Verbete }=\text { entrada }+ \text { categorial gramatical }+ \text { definição }+ \text { contexto } .
$$

Lembrando que em relação à definição, teremos o cuidado de apresentar todas as acepções conhecidas pela comunidade, identificando como definição 1 e definição 2, apresentando exemplos de cada um dos sentidos expostos. Como nos seguintes exemplos:

BACURI - s.m. 1. Porco pequeno, 2. Menino.

Ex: 1. Leve a lavagem para o bacuri. 2. Esse bacuri já fala que nem homem feito. BATERIA - s.f. 1. Suporte para guardar panela, 2. Pilha.

Ex:1. Pegue a frigideira na bateria. 2. Compre a bateria para o rádio. BAQUE - s.m. 1.Queda. 2. Susto

Ex: 1. Só ouvi o baque do menino. 2.Levou um baque com a notícia.

\footnotetext{
${ }_{5}^{5}$ Maviael Melo é músico, poeta e cordelista, voltado à vida cultural de Pernambuco através da internet e da participação em eventos de cantoria e recitação. Atualmente, vem trabalhando como arte-educador ambiental na Bahia e em Pernambuco.
} 
DESPACHAR - v. 1. Mandar embora. 2. Expelir a placenta depois do parto.

Ex: 1. Já despachou o vendedor? 2. A cabra ainda não se despachou.

FÔJO - s.m. 1. Armadilha, 2. Lugar sujo, desarrumado.

Ex: 1. Armou o fojo no cercado. 2. Seu quarto parece um fojo.

Dessa forma, continuaremos as atividades através da explicação sobre a pesquisa extraclasse. A turma será organizada em grupos de acordo com a localidade em que reside. Os grupos menores ficarão somente com a pesquisa e organização dos verbetes e serão orientados a listar todas as palavras em ordem alfabética, classificá-las de acordo com a classe gramatical de cada uma, dando-lhes também o significado. Já os grupos maiores, além da pesquisa dos verbetes, irão pesquisar causos e ditos regionais, sendo que eles deverão explicar o sentido de cada expressão, de forma que todos compreendam, como nos exemplos que seguem:

NÃO TIREI PAPAGAIO DO ALFOJE NEM GALINHA DO ESPETO.

Pessoa acostumada a falar com alguém e de repente "fica de mal". QUEM INCHA SEM DOENÇA DESINCHA SEM REMÉDIO.

Pessoa acostumada a falar com alguém, de repente "fica de mal" e depois de algum tempo volta a falar sem explicação.

SÓ SE CONHECE ALGUÉM QUANDO SE COME SAL JUNTO.

Só se conhece realmente uma pessoa quando passa a conviver com ela. ALÉM DE PORCA, MAL PELADA.

Uma pessoa que já tem algum defeito e com o tempo adquire muitos outros.

Dentro desse contexto, certamente serão descobertas as origens de alguns dos verbetes e expressões e notar que todos eles têm forte ligação com a história de cada comunidade, com a cultura de seus moradores, pois como afirma Aragão (2010) o estudo do léxico da língua de uma determinada região reflete a descrição da cultura dessa comunidade, a ideologia, as lutas e a história desse povo. Sendo assim, não é possível estudar a língua sem relacioná-la com a sociedade e a cultura nas quais o falante está inserido.

\section{d. Socialização da aprendizagem:}

Por fim, após a realização da pesquisa extraclasse coletando as expressões e verbetes específicos de suas localidades, será feita a organização de uma coletânea de verbetes regionais, de causos e expressões de moradores da comunidade, dando origem ao Dicionário Regional de Uauá, o qual será apresentado para toda escola.

\section{e. Avaliação:}

A prática avaliativa desta proposta estará centrada no processo e na continuidade da aprendizagem, isto é, será processual e contínua, levando em consideração a participação e o envolvimento nas atividades propostas durante o projeto.

\section{CONSIDERAÇÕES FINAIS}

Esse artigo buscou apresentar uma proposta didática que contemplasse práticas de valorização do falar sertanejo entre os estudantes da Educação Profissional e Tecnológica, através da oficina "Nossa Cultura, Nossa Língua". Pretende-se que esta atividade possibilite o estudo sobre a linguagem específica da nossa região de maneira prazerosa e dinâmica, tendo em vista que esta atividade aguçará a curiosidade do estudante sobre a dimensão lexical que os verbetes e seus significados proporcionam. 
Essa afirmação é reforçada por Pereira (2008) quando expõe que a escola deve contribuir para que o estudante adquira a competência para entender e utilizar a própria língua. Contudo, é necessário que este estudo esteja pautado em conhecimentos significativos para o aluno. Só assim, o estudo da língua portuguesa será produtivo e significativo para o estudante.

Sabe-se que, nesse sentido, há muito a ser feito e a inclusão dessa prática de valorização do falar regional contribuirá para a atuação do aluno como cidadão que participa e discute problemas e questões importantes para sua vida e para a comunidade onde vive.

Nossa proposta inclui a pesquisa lexicográfica, prática que não é comum para estudantes do Ensino Médio, poderá haver certa dificuldade tanto por parte dos alunos, quanto dos professores, mas, ao longo de um trabalho contínuo e regular, as práticas de pesquisa lexicográfica em nossas salas de aula serão tão comuns como as de leitura e escrita e isso poderá gerar reflexos positivos no desempenho linguístico de nossos alunos, haja vista que é uma atividade que incentivará o respeito do dialeto regional e dessa forma amenizará a prática do preconceito linguístico.

\section{REFERÊNCIAS}

ALENCAR, C.C.L. História do Cordel. Disponível em: http://www.cordelon. hpg.ig.com.br/historia_cordel.htm. Acesso em 11/02/2019

ARAGÃO, M. S. S. A Linguagem Regional-Popular no Nordeste do Brasil: Aspectos Léxicos. In: IX Simpósio Internacional de Comunicación Social, 2005, Santiago de Cuba. IX Simpósio Internacional de Comunicación Social - Actas I. Santiago de Cuba Cuba: Centro de Lingüística Aplicada - Santiago de Cuba, 2005. v. I. p. 457-459. Disponível em: http://www.profala.ufc.br/Trabalho2.pdf. Acesso em 01.03.2019

BARBOSA, Lúcia Maria de Assunção. O conceito de lexicultura e suas implicações para o ensino-aprendizagem de português. Filol. Linguíst. Port. n. 10-11, p. 31-41, 2008/2009.

BRASIL/MEC/SEF. Parâmetros Curriculares Nacionais: Ensino Médio. Brasília: Ministério da Educação, 1999.

BIDERMAN, M.T.C. Os dicionários na contemporaneidade: arquiteturas, métodos e técnicas. In: OLIVEIRA, Ana M. Pinto Pires de; ISQUERDO, Aparecida Negri. As ciências do léxico. $2^{\mathrm{a}}$ Ed. Campo Grande: Editora UFMS, 2001. p. 131-144. Disponível em: http://acd.ufrj.br/ pead/tema05/formacaolexico.html. Acesso em 10.05.2019

BUSSATO, C. Contar e Encantar: Pequenos segredos da narrativa. $5^{\text {a }}$ Ed. Petrópolis, RJ: Vozes, 2008.

DIONÍSIO, Ângela Paiva. Gêneros textuais e ensino. $5^{\mathrm{a}}$ Ed. Rio de Janeiro: Editora Lucerna, 2007.

FARACO, Carlos Alberto. Norma culta brasileira: desatando alguns nós. São Paulo: Parábola Editorial, 2008.

ISQUERDO, A. Negri. A propósito de dicionários de regionalismo do português do Brasil. In: ALVES, I.N.; ISQUERDO, A.N. (orgs). As ciências do Léxico. Campo Grande: 
UFMS, 2007. Disponível em: http://www.mel.ileel.ufu.br/gtlex /viiengtlex /pdf/ . Acesso em 16.05.2019

Léxico em tempo e espaço: a questão dos regionalismos. In: MARIN, Jérri R.; VASCONCELOS, Cláudio A. (orgs). História, região e identidades. Campo Grande: UFMS, 2003. Disponível em: http://www.mel.ileel.ufu.br/gtlex /viiengtlex /pdf/ . Acesso em 16.05.2019

LUYTEN, Joseph. A notícia na literatura de cordel. São Paulo: Estação Liberdade, 1992.

MELO. Maéve. Letramento e a Literatura de Cordel na Sala de Aula. Universidade do Estado da Bahia. Campus III. Juazeiro, 2009.

PEREIRA, Sheila de. Carvalho. A importância dos campos léxicos no ensino de língua portuguesa. Uberaba UFTM v. 1 p. 186-208 2008 - jan. / jun. Disponível em http://revistaintertexto.letras.uftm.edu.br/ Acesso em 10.05.2019.

SOARES. Magda B. Concepções de linguagem e o ensino da língua portuguesa. In: BASTOS, Neusa (org.). Língua portuguesa: história, perspectivas, ensino. São Paulo: Educ, 1998 